\title{
EL HERALDO DE PARÍS (1900-1904): POESÍA NECESARIA
}

\author{
CHRISTIAN MANSO \\ christian.manso@univ-pau.fr \\ Université de PAU
}

\section{Resumen}

Fundado y dirigido por Luis Bonafoux, el Heraldo de París fue un periódico regeneracionista por excelencia y no fundamentalmente literario a priori. Concedió sin embargo un espacio a la poesía en su proyecto editorial. Es el objeto de esta aproximación en este estudio monográfico.

Palabra clave: Expresión poética finisecular de combate. Regeneracionismo. Rosario de Acuña, Vicente Medina, Manuel Paso.

\section{Abstract}

Founded and edited by Luis Bonafoux, the Heraldo de París was more a regenerationist newspaper than a literary one. It dedicated, however, some space for poetry in its editorial line. In this respect, the approach in this monograph is perfectly relevant.

Keywords: Turn of Century Poetry of Resistance. Regenerationism. Rosario de Acuña, Vicente Medina, Manuel Paso

Tras la publicación parisiense del semanario La Campaña que desde la capital francesa trata esencialmente de España, con la protectora barrera pirenaica de por medio (Manso, 1998a:169), el desterrado Luis Bonafoux se lanza a otra aventura periodística creando el 20 de octubre de 1900 un novedoso rotativo titulado Heraldo de París. Impreso en un formato habitual en la época (39 centímetros de largo por 27 de ancho), consta de 4 páginas, estando las 3 primeras integradas por 5 columnas dedicadas a las colaboraciones de 
los periodistas, y la última destinada a los anuncios publicitarios (Pommade Royer, Vino Nourry, Jabón «Forest City», hasta billetes despachados a bajo precio por la Estación de Saint-Lazare para el trayecto París-Londres). Si al principio su difusión observa el ritmo semanal de publicación anunciado (hasta el 20 de mayo de 1901), se va a volver caótica a partir del lero de junio de ese año, y también a todo lo largo del año de 1902 cuyo último número está fechado en 24 de noviembre. Escaseará substancialmente en 1903 con tan sólo 2 números (3 y 22 de diciembre), asimismo en 1904 en que aparecen 8 números. Se concluirá definitivamente el Heraldo de París el 27 de mayo de 1904 arrojando un balance de 69 números. De buenas a primeras no se ha de considerar como un vector literario: sigue con la tendencia general de su predecesor parisino, a saber un órgano de prensa de combate que con su mismo título, La Campaña, se había puesto resueltamente al frente de la misma causa que la que defendía el propio Emile Zola. Ni que decir tiene que, en consideración al anarquizante pontífice de las Letras francesas, la literatura se había de descartar, ni mucho menos. Se había de concebir como una formidable potencialidad creativa al servicio de «la verdad sola, toda la verdad» (Manso, 1998a: 169). No es ocioso recordar al respecto que en aquel entonces España vivía el trauma persistente de la catástrofe de 1898 que algunos jóvenes intelectuales intentaban yugular vehementemente con un radicalismo progamático de renovación, requiriendo insistemente este último la mediación de la misma literatura. Así que el título de esta nueva publicación, Heraldo de París, no es nada anodino en esa contextualización tan particular a nivel binacional: deja traslucir, indudablemente, la imagen popular de la fama pintada en forma de doncella que además de volar por los aires -y sobrevolar las fronteras geográficas- va embocando la trompeta para difundir relevantes sucesos, nuevas primordiales y por supuesto la misma verdad. Y esto desde París, o sea desde el faro del mismo humanismo, donde, como indica un recorte sacado de la prensa francesa: «notre vaillant confrère Luis Bonafoux qui, dans le Heraldo de Paris, dont il est le directeur, raconte en France ce qu'il est défendu de dire en Espagne» (Express de Paris, 1900).

Para hacerse una idea exacta de la esencia del Heraldo de París, nada más pertinente acercarse a la personalidad del que no sólo lo dirigió sino que lo fundó. Destinado, ante todo, a un público que reside en España, y dirigido por un redactor-jefe que tuvo que huir de este país y refugiarse en Francia por no sufrir las represalias de buena parte de la sociedad tradicionalista y levítica de finales del siglo XIX, este periódico es el reflejo de una conciencia política impregnada de un característico espíritu epocal que sustenta la crítica satírica, tal y como lo puso particularmente en evidencia Martínez Ruiz en La crítica 
literaria en España, discurso que pronunció en el Ateneo Literario de Valencia el 4 de febrero de 1893 (Martínez Ruiz, 1893). Dos artículos al respecto vienen de perlas, que son indicios preciosos. El primero está firmado de Zeda que aprovecha la ocasión de la salida de un nuevo libro de Bonafoux, París al día, para esbozar un retrato ideológico-moral del escritor-periodista: «Porque Bonafoux es un romántico, cuyo corazón se indigna contra todas las iniquidades y brutales egoísmos, aceptados y hasta ensalzados por el elemento mangoneador de nuestros días. Todos los caídos le inspiran piedad, los desgraciados lástima, todos los miserables delicada ternura (...) El humorismo de Bonafoux me recuerda el de Larra: sus chistes rebosan siempre amargura. Piensa, y así lo dice, que «suprimir lo amargo es...suprimir el fondo de la vida». A veces su lenguaje es de una extrema crudeza. No faltan espíritus timoratos, esclavos del eufemismo que censuran a Bonafoux por sus libertades de palabra» (Zeda, 1900). Esta confluencia de demofilia y de humorismo -negroson rasgos que remiten a un tardorromanticismo vigente, por supuesto, en el afán regeneracionista proclamado por todos aquéllos que pretenden, en los albores del siglo Xx, imprimirle a España un derrotero desembarazado de hinchazones, monsergas y verborreas. La voz de Bonafoux en esta obra consagrada al «monstruoso concierto o desconcierto de 300000 voces humanas» (Zeda, 1900), de la capital francesa no puede ser más adecuada con esa ansia de ajustarse a rajatabla a la realidad circundante: «Bonafoux recoge todos estos ecos de la vida parisiense y los transmite a sus numerosos lectores, sin falseamientos retóricos y con una sinceridad que traspasa algunas veces los límites de los convencionalismos literarios vigentes en la España actual, pero que revelan siempre intención honrada y alta idealidad» (Zeda, 1900). Que esta escritura propenda a veces a un realismo, y hasta a un naturalismo, no es nada extraño habida cuenta de la herencia zoliana del escritor-periodista. Lo que no obsta para que se manifieste a las claras un subjetivismo plenamente asumido que abre, por ende, la vía al modernismo. El segundo lo firma Blasco Ibáñez que, a su vez, saca partido de la circunstancia para perfilar tanto física como espiritualmente al escritor-periodista: «Los crímenes, las locuras y los desenfrenados placeres de París, las ridiculeces de la burguesía francesa; los dramáticos incidentes de la cuestión Dreyfus, todo aparece artísticamente desordenado en este libro, como una conversación pintoresca e ingeniosa sostenida entre Bonafoux y el público» (Blasco Ibáñez, 1900). El punto de vista de Blasco Ibáñez que complementa con más concisión el de Zeda, es de mucho interés por cuanto pone de realce más nítidamente el papel transnacional del escritor-periodista en su combate universal por los derechos humanos, la justicia social y en contra de todas las formas de discriminación. Con lo que 
se justifica plenamente que abogue por esta nueva modalidad de literatura de suma eficacia anteriormente aludida y corroborada por Blasco Ibáñez: «El público adora a los escritores que dicen lo que sienten, y bajo una aparente frivolidad, son más probos y rectos que los hombres serios» (Blasco Ibáñez, 1900). Tras este primer acercamiento a la línea del periódico que se le brinda al lector, otro indicio complementario se le facilita un artículo informativo sin firma insertado en la página 2 del número del 22 de diciembre de 1900. Titulado En la Sorbona, da constancia de una conferencia que dió en esta famosa universidad el miércoles pasado el mismo secretario de la redacción del Heraldo de París, don Francisco Villanueva, acerca de la Situación de España después de la pérdida de sus colonias. En efecto, el argumento de esta disertación que viene resumido en este texto aclara meridianamente lo que conviene llamar la razón de ser del periódico: «Puso de manifiesto (el conferenciante) la desorganización política y la inmoralidad que reina en aquella nación. Villanueva no hizo una conferencia original. Fue un confeccionador hábil pues para dar idea del estado actual de España, leyó el soneto de Rosario de Acuña, «España a fines de siglo», algunos párrafos del ilustre Pi y Margall sobre la cultura española, algo de Costa acerca del porvenir de España y recortes de aquella crónica en que nuestro director hablaba de la propiedad y de la religión y de la familia y del «robo en rosca». Todo combinado de tal manera que hizo explosión horrorizando al auditorio cuando habló de Montjuich, diciendo que no es un castillo maldito, sino una institución vergonzosa y repugnante, que trata de resucitar los horrores inquisitoriales y que amenaza destruir las ideas más elementales de la civilización en España. Fue muy aplaudido» (S/f, 1900a). Con las referencias a Pi y Margall de quien se publica el reciente discurso en las Cortes en contra del restablecimiento de la ley del 2 de septiembre de 1896 destinada a perseguir a los anarquistas (S/f, 1900b), a Costa que con motivo de la celebración del Congreso Ibero-Americano hace un balance amargo y crítico de la agónica España (Costa, 1900), a Bonafoux para quien «el clero tiene toda la culpa de la actual situación de España» (Bonafoux, 1900), es posible inferir poco a poco de este artículo el denominador común que reúne a los colaboradores de esta publicación. A ellos se suman otras personalidades ya conocidas en el amplio abanico de los regeneracionistas, entre los cuales reina ostensiblemente una variopinta acracia: Tárrida (Tárrida del Mármol, 1900), Rodrigo Soriano (Soriano, 1900), R. Mella (Mella, 1900), Manuel Bueno (Bueno, 1900), Eusebio Blasco (Blasco, 1900), W. Tcherkessof (Tcherkessoff, 1900), Roberto Castrovido (Castrovido, 1900), Aramis (Bonafoux, 1900 a), R. Burguete (Burguete, 1901), Fray Candil (Fray Candil, Bobadilla, 1900), etc. Sin embargo el objeto de este estudio que pretende ceñirse al 
ideario que paulatinamente emerge de toda esta textura, esta tesitura, ideológica, no va a tantear el estado de esta cuestión en el campo de la muy arraigada y acostumbrada prosa, ya que, como se advirtió, a este fin se le ofrece al lector una vía bastante original. Con efecto, antes de mencionar a los tribunos consagrados de la causa que abraza, el artículo anunció prioritariamente un texto poético, el soneto de Rosario de Acuña, España a fines de siglo. Precedido de un retrato de medio cuerpo miniaturizado de la poeta y de un homenaje a la «primera española contemporánea, la primera por la inteligencia, y lo que vale más, por el corazón; por el odio que su corazón profesa a todo lo injusto y por el amor que tiene a todo lo noble. Una mujer así es una excepción en todas partes. Es un acontecimiento en España» (S/F, 1900 c), este poema apareció el 8 de diciembre de 1900. De ahí que dentro de ese amplio territorio de militancia marcadamente subversiva se abra un espacio nuevo, poético, que el Heraldo de París pone particularmente de relieve, espacio que además va a cultivar, asociando este género a su combate, como si la poesía se hubiera de considerar como un a modo de quintaesencia del mismo. El soneto de Rosario de Acuña, si «está bien para los que aguardan», según Lope de Vega (Vega Carpio, 1948: 17), no puede ser más tajante por lo que lleva implícito. Es un cuadro despiadado, tétrico, de la España de finales/ principios del siglo Xx, cuyo poder expresivo radica ante todo en la misma forma poética elegida que implica condensación y síntesis, las cuales en este caso vienen expresadas por formulaciones lapidarias y apodícticas. Empieza por una visión cáustica del pueblo español en general aprehendido en lo que más lo caracteriza según la poeta, a saber su fiesta nacional: «Muchas plazas de toros donde chilla/ muchedumbre de brutos sanguinarios» (Acuña, 1900). Ya aparecen con estos dos primeros versos lo que va a sustentar su argumento: el estancamiento de una sociedad de mentalidad primitiva ajena a la marcha del progreso civilizador, al desarrollo de sus facultades intelectuales, morales y físicas: «juventud de maricas, o sectarios;/ infancia que en sus pedreas se acribilla» (Acuña, 1900). De cara a tan alarmante y desastrosa situación, unos impávidos oligarcas, dignos herederos de la colonización árabe y depredadores de los bienes nacionales, un prepotente enjambre de mequetrefes aferrados a unas inveteradas costumbres gobernadas por la desidia, la inercia y la impericia -como son los funcionarios de estado y los políticos-, y por fin una plaga de religiosos que en su mayoría gozan de pésima reputación, mostrándose unos y otros insaciables afanosos al lucro. El resultado, en tales condiciones, no puede ser más desolador y devastador: un clima deletéreo de depravación moral que a la par que instiga al desenfreno y al vicio es una lacra para cualquier intento de incremento del país: «Taifa que vive bien de lo que pilla; los que manda lejión (sic) 
de rutininarios, turba de jesuitas y falsarios/ que envuelta en oro deslumbrante brilla./ La envidia en trono; el ocio a sus anchuras:/ tribus de prostitutas y de ratas;/ hambre, ignorancia, piojos, salvajismo;» (Acuña, 1900). La conclusión es sin apelación: entre la cúspide del Estado y su base existe una relación especular. Es ineludible. Pero antes de terminar siente la necesidad la poeta de insistir otra vez en lo que perjudica profundamente a España: una considerable población constituida por fuerzas muertas. Con lo que su vaticinio no puede ser más categórico: «Fango en las cumbres; cieno en las honduras:/ muchos frailes, mendigos y beatas.../ ¡Así camina España hacia el abismo!» (Acuña, 1900). ¿No se podría contemplar en la perspectiva lopesca un radical y poderoso antídoto perfectamente capacitado para extirpar de cuajo toda esta lacra orgánica y moral? Un poco antes de publicar este soneto, Rosario de Acuña había insertado otro dedicado Al siglo XIX que se presentaba en la misma vena, la misma tonalidad poética de amargura y desdén. La primera nota, la que resume sintéticamente el juicio que emite la poeta sobre el siglo extinto, se la dicta una conciencia profundamente revuelta por el mayúsculo menosprecio que ostentó este último respecto del pueblo en general: "iHuye, siglo, a esconderte en las edades/ que contarán el salvajismo humano!» (Acuña, 1900 b). Lo que lo retrotrae a épocas pretéritas sumidas en la barbarie y lo designa como el exponente de la más acérrima negación de la marcha de la humanidad hacia el progreso. Valiéndose de algunas palabras significativas para caracterizar el sello distintivo de este siglo, señala su relevante y escandalosa contradicción: «en ciencia, industria y artes soberano,/ también fuiste gigante en crueldades» (Acuña, 1900 b). Conque, por más chocante que fuese, los avances tan descollantes de tal período no se compaginaron con el mejoramiento del pueblo; todo lo contrario. Es como si toda esta radiante y encumbrada civilización científica, industrial y artística se hubiera vuelto en contra de éste último; como si esta relación no se hubiera podido concebir sin la acción combinada de estos dos aspectos irreductibles y contrarios. Tras este balance pernicioso y abyecto por haber sido el auge de este siglo proporcional a su deshumanidad, Rosario de Acuña repasa, siempre con la mayor economía de medios expresivos, lo que fue este siglo que inauguró una nueva era con el advenimiento del Nuevo Régimen sellado por las Cortes de Cádiz y la Constitución de 1812. Detrás de sus palabras se trasluce el mayor adelanto que redundeó en beneficio de la nación española: la soberanía nacional con lo que llevaba aparejado en materia de libertades y de derechos individuales, o sea lo que más cuenta a sus ojos. El paso decisivo dado hacia la emancipación del pueblo es, sin duda alguna, lo que más valoriza la poeta. Evolución destacadísima que no se pudiera imaginar sin el principio fundador de la Carta Magna: 
la racionalizacón de la organización de la sociedad que de una vez para todas parecía erradicar aberraciones seculares. Desgraciadamente el fin de este siglo se señaló por su involución; resultó un sueño abortado del que surgió un engendro malévolo que a imagen de la hidra tuvo varias cabezas como el anacrónico caciquismo, la desvergonzada oligarquía, las violentas represiones en Andalucía, Asturias, País Vasco, las sangrientas guerras coloniales, cuya víctima fue siempre la misma, a saber el pueblo: «Nacido entre radiosas libertades,/ de la razón te apellidaste hermano,/ y al fin mueres en lecho de tirano,/ hydrópico (sic) de vicios y maldades» (Acuña, 1900b). El fin del poema vuelve al principio, como un ritornelo mediante el apóstrofe anáforico, cuya exclamación imprecatoria, da cuenta de la abominación que lleva albergada la poeta, en relación con el agrio desengaño que suscitó en ella este siglo; cifra, al fin y al cabo, en el pandemónium de los más absurdos atropellos. Para concluir vuelve incansablemente a lo que considera como la característica de este siglo: su tremenda contradicción. Ahora la enfoca en otro campo que remite a su objeto de mayor preocupación: mejorar la suerte del pueblo. Lo que, con ese radical cambio de principios de siglo, se anunciaba como la toma en cuenta de la dimensión humana primordial en su opinión, que probablemente se refiere a a la tercera palabra constitutiva del lema de la revolución francesa, «libertad, igualdad, fraternidad», se ve violentamente pisoteado. Vuelve la alusión al más masivo y odioso atentado perpetrado contra la vida del pueblo y consecuentemente a lo que desató un clima social de explosiva tirantez: «si una brisa de amor meció tu nido/ la sangre humana orló tu vestidura,/ y te dejas al hombre sumergido/ en el fangal del odio y la amargura» (Acuña, 1900b). La importancia concedida a Rosario de Acuña es innegable: no podía faltar en este concierto combativo de principios de siglo la voz de la poeta para denunciar con sus medios tan vibrantes la cruenta mofa que desde la cumbre del poder se hace de la inmensa mayoría, la negación de solidaridad, la falta de altruismo que les fueron consubstanciales a los timoneles de España. Estos dos únicos poemas publicados por el Heraldo de París testifican, por tanto, su voluntad de asociar estrechamente la poesía a su lucha cotidiana por la dignificación de los de abajo. Es lo que viene explícito en el largo artículo que publica el escritor argentino Alberto Ghiraldo el 7 de julio de 1902, titulado El ideal del arte, en el que en particular hace hincapié en el papel que desempeña la poesía: " $i$ Que han de hacernos llorar dolores convencionales y añejos cuando a la vista, tan cerca de nuestros ojos, tenemos tanto dolor fresco, que simboliza pena social, floreciendo en flores rojas y prolíficas! ¡Oh, poetas, hermanos míos! lanzad las cuadrigas de vuestras estrofas en pos del dolor actual, que es el de todos, ese dolor que irrumpe a gritos de las estepas 
de Rusia, de los muros de Montjuich, de las guillotinas de Francia, de las horcas de Chicago! (...) Advertid que tenéis frente a vosotros, para estudiar de cerca ejemplares de héroes como Kropotkine cuya odisea a través de la Europa, propagando el principio de un ideal jigante (sic), encierra más poesía que todas las luchas egoístas empeñadas por czares y emperadores, caciques y presidentes de repúblicas. Escribid (...) la epopeya de la idea nueva, llevada victoriosa a través de todas las sombras proyectadas por las bayonetas, sables, fusiles y patíbulos erguidos como murallas de errores ante la verdad» (Ghiraldo, 1902). Al lado de Rosario de Acuña se encuentran bastantes poetas que, manifiestamente, profesan este mismo ideal revolucionario, entre los cuales destaca la personalidad del murciano Vicente Medina. De éste aparecen nada menos que 24 poemas a todo lo largo de los 69 números que cuenta la publicación, llevando 5 de ellos la mención especial de «Para el Heraldo de París». Ya en la Página literaria de La Campaña del 12 de marzo de 1898 Martínez Ruiz había llamado la atención de sus lectores sobre Vicente Medina con un artículo, Un poeta, dedicado a su poemario, Aires murcianos, de reciente aparición (Manso, 1998b). A su vez, el 15 de agosto de 1902, Luis Bonafoux le dedica una Crónica, La Malvaseda, en la que aprovecha la ocasión de la salida del libro de poemas del murciano, La canción de la vida, para acercarse a su personalidad, a su genio, a su compromiso. Para Bonafoux la profunda tristeza de sus versos, que emana de una rara sinceridad, hace de Medina un poeta honrado, digno del mayor respeto. Su Canción que ofrenda a los suyos y que hace eco a su más íntima existencia, la contempla Bonafoux simbolizada por una lágrima: «Su vitriolo es la lágrima que se hincha por sí sola, que se desborda del corazón y que, desbordada mansamente, va rociando el recuerdo de las madres (...), las acacias, los amores y las penas de su alma, y la senda hermosa sobre toda ponderación, su senda que se la han borrado» (Bonafoux, 1902). Por el irrepetible idilio huertano que antaño le procuró al poeta, esta senda -por idéntica que pueda parecer al presente- está ya desprovista de ese tan entrañable tropismo amoroso, con lo cual se convierte, por consiguiente, en un objeto de mortificación. Por descontado que este prístino objeto de amor íntimamente ligado a la tierra, a la huerta murciana, encierra todo un universo polisémico sugerido al albedrío del lector. Este tono tan lastimero e identitario es, para Bonafoux, lo que forma ontológicamente el estro del poeta, que hasta perdura en sus textos más virulentos: «Medina no se despinta (...). Hasta cuando canta, en sus Sectarias, en Alma del pueblo, los grandes ideales de la Humanidad, que, según el gran escritor argentino Alberto Ghiraldo, deben ser único tema del poeta contemporáneo, y fustiga las injusticias sociales, Medina los canta entre sollozos y las fustiga con hojas de malvaseda 
que... «es sufrida, en todo tiempo/ me da su olor» (Bonafoux, 1902). Con su Crónica, y siempre con esta voluntad de dar fe a su propósito, Bonafoux tiene a bien publicar un largo extracto de En la Senda (Medina, 1902). Al examinar los textos de Vicente Medina exclusivamente reservados al periódico, el lector puede sacar en claro los componentes de lo que conviene denominar la ideología del poeta. En Sectarias, o sea un conjunto de diferentes estrofas en las que predominan los sextetos de formas plurimétricas tan de moda en el modernismo, pone de realce el poeta la abrumadora y estridente desigualdad social sufrida por los obreros cuya existencia parece condenada a un sempiterno vía crucis: «Los obreros marchan,/ de un burgués en entierro lujoso/ llevando la caja./ Los obreros marchan,/ ¡del burgués, hasta muerto, pacientes/ sufriendo la carga!» (Medina, 1901). ¡Son los sinceros!, a base de 4 cuartetos de endecasílabos de rima asonantada, es de concebir como una urgente llamada a la moral pública y personal que lanza el poeta de cara al fariseísmo y a la vanagloria triunfantes, haciéndose el defensor de los desinteresados, de los altruistas que, a pesar de la corruptela, del quebranto ético, no dudan en actuar rectamente: «Dejadles paso, que son sencillos,/ que son humildes, que son ingenuos.../son los que tienen la valentía/ de sus acciones...json los sinceros!» (Medina, 1901a). ¡Id vagos! que aparece poco después, formado por una silva asonantada -de factura tan modernista también-, vapulea a los empingorotados, haraganes, acomodados y noctívagos que viven holgadamente a costa del trabajo de la clase obrera, intimándoles a concienciarse cuanto antes de la situación y de la condición a que se ven reducidas las masas por su propio descaro, su frivolidad y a ser posible a enderezar su conducta: «los de raza distinta y poseedores/ únicos del honor y la nobleza, / canallas perfumados/ de dorada ralea:/ madrugad con el sol, id donde explotan/ con saña vil a las humanas bestias.../id a los campos, id a los talleres,/ a los lóbregos antros de la tierra./ ¡Id, vagos! que confío/ en que habéis de sentir, cual yo, la afrenta» (Medina, 1901b). La más honrosa banda, otra silva asonantada compuesta de heptasílabos y de endecasílabos, se fija en el oficio que ejerce el mozo de cuerda, oficio comparado al de un militar por semejarse a un combate cotidiano, a una lucha encarnizada por su propia supervivencia, sin embargo con una diferencia de importancia: «A pesar de que lleva una campaña/ de servicio bestial de años más años,/ no ha podido ascender, ni su retiro/ pedir para el descanso» (Medina, 1901c). Ese «octogenario», ese mozo exhausto, por muy indignante que sea, no tiene más remedio que seguir imperturbablemente en el tajo y sin rezongar. Este operario tan cumplidor despierta, por supuesto, la admiración del poeta a la par que merece toda su consideración: «y el respeto más grande de la vida/ he sentido por él al contemplarlo/ ¡con la gastada 
cuerda sobre el pecho/ como orgullosa banda de soldado!» (Medina, 1901c). Este ser de humilde extracción que tiene a honra oficiar tan dignamente, puede transparentar para el poeta una potencialidad de militancia y de pugna en el tenso contexto social contemporáneo. El Dios es la fuerza, otra silva asonantada formada de heptasílabos y endecasílabos, es un grito de hondo hastío del «hombre bueno, crédulo, honrado», explotado desde la noche de los tiempos por los «expoliadores de la tierra», a quien asalta la duda respecto de la misma existencia de Dios: «¿Pero en dónde está Dios! ese Dios justo/ que redime el dolor y lo compensa?/ ¿Acaso Dios existe?/» (Medina, 1901d). Sin la menor señal de ese redentor y soportando todas las humillaciones perpetradas por los de arriba, le cae en mientes la respuesta que más lógica le parece: «Sacudido a un impulso poderoso/ de rebelión suprema, / clarividente tuvo/ de Dios la exacta idea:/ con pavoroso acento/ que estremeció la tierra,/ como lanzando

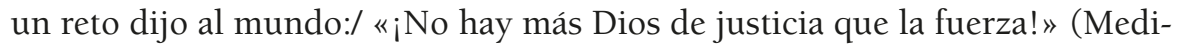
na, 1901d).

Se podrían añadir otros muchos textos de la misma coloración poética, como los de Vicente Colorado (Colorado, 1901), Pedro Barrantes (Barrantes,1901), Nicolás Estévanez (Estévanez, 1901), etc., o también de un anónimo poeta «detenido en el Pelayo» de Barcelona (Anónimo, 1901), y todavía del poeta granadino Manuel Paso que fallece a principios de 1901 y al que Bonafoux tributa un homenaje, por integrarlo dentro del batallón de los que comparten sus mismos objetivos, y por tanto, dentro de los que sufrieron para que triunfaran sus ideales humanistas: «También a ti atropellaron mil veces, y siempre impunemente, los poderosos, los fuertes y los malos; y has muerto sin el consuelo de que se te secara el índice de la diestra sobre la pluma de la sátira y la invectiva» (Bonafoux, 1901). Le publica en tres entregas trozos de su poemario Nieblas (Paso,1900, 1901a,b), otra composición lírica, A la Alhambra (Paso, 1901c), y un soneto, A Dios (Paso, 1902) en el que harto de las ignominias del bifronte sojuzgador de su país, la Iglesia y el Gobierno, en tono deprecatorio se dirige el poeta a Dios en los términos siguientes: « ¡ baja otra vez a ser sacrificado!/ ¡vuelve Señor a redimir el mundo!» (Paso, 1902). Con todos los datos ya enunciados, la dimensión poética de este órgano de prensa no puede ser más obvia. Es una dimensión en la que, desde luego, habría que insistir y que descubre a otras figuras que hasta ahora quedaron algo marginadas. Tanto los prosistas como los poetas participaron en este vasto movimiento de movilización patriótica que se denominó «regeneracionismo». La introducción en el título de este artículo de un anacronismo voluntario con una cita tan mínima como trascendental sacada de Gabriel Celaya 
(Celaya, 1960:49), responde, ante todo, a esta preocupación de equiparar los roles y restablecer algún tanto la verdad de los hechos.

\section{Bibliografía}

Heraldo de París. Se publica todos los sábados. Redactor-Jefe: Luis Bonafoux. Redacción y Administración: 9 rue Lamartine. Paris.

ACUÑA, Rosario de (1900a), «España a fines de siglo», Heraldo de París, 8-12.

- (1900b), «Al siglo XIX», Ibid, 4-11.

Anónimo (1901), «Barcelona», Ibid, 22-06.

ARAmis (Bonafoux, Luis) (1900), «París. La colonia española», Ibid, 22-12.

BARRANTES, Pedro (1900), «El emperador de España», Ibid, 23-03.

BLASCO, Eusebio (1900), «Catalinaria», Ibid, 8-12.

BLASCO IBÁÑEZ, Vicente (1900), «Un libro de Bonafoux», Ibid, 27-10.

BONAFOUX, Luis (1900), «Todos curas», Ibid, 11-11.

- (1901), «A Manuel Paso en el cementerio», Ibid, 26-01.

- (1902), «Crónica. La Malvaseda», Ibid, 15-08.

BuENO, Manuel (1900), «Una boda», Ibid, 11-11.

BURGUETE, R. (1901), «A.W. Tcherkessoff», Ibid, 21-01.

CASTROVIDO, Roberto (1900), «Madrid», Ibid, 22-12.

Celaya, Gabriel (1960), «La poesía es un arma cargada de futuro», en Poesía

Urgente, Buenos Aires, Editorial Losada. pp.49-50.

Colorado, Vicente (1901), «Pueblo de mendigos», Heraldo de París, 2-02.

COSTA, Joaquín (1900), «El porvenir de España», Ibid, 24-11.

ESTÉVANEZ, Nicolás (1901), «El Cid», Ibid, 6-04.

Express de Paris (1900), «La intriga se aclara», Ibid, 29-12.

FRAY CANDIL (E. Bobadilla) (1901), «Baturrillo. La moral en el arte», Ibid, 21-01. GHIRALDO, Alberto (1902), «El ideal del arte», Ibid, 7-07.

MACEIN, Francisco (1900), «Crónica», Ibid, 8-12.

MANSO, Christian (1998a), «Sobre el semanario parisiense La Campaña de Luis Bonafoux», en Azorín et la génération de 1898, Pau, Covedi, pp.169-179.

- (1998b), «Vicente Medina, chantre de la terre murcienne», en Pays de la langue, Pays de la poésie, Pau, LRLLR et Editions Covedi, pp.109-114.

MARTínez Ruiz, José (1893, 1959), «La crítica literaria en España», en Azorín, Obras Completas, I, Ed. Ángel Cruz Rueda, Madrid, Aguilar.

MedinA, Vicente (1902), «En la senda», Heraldo de París, 15-08.

- (1900), «Sectarias», Ibid, 11-11.

- (1901a), «iSon los sinceros!», Ibid, 6-05.

- (1901b), ¡Id vagos!», Ibid, 1-06.

- (1901c), «La más honrosa banda», Ibid, 8-07.

- (1901d), «El Dios es la fuerza», Ibid, 31-10. 
Mella, Ricardo (1900), «Errico Malatesta», Ibid, 27-10.

PASO, Manuel (1900), «Nieblas, I», Ibid, 29-12.

— (1901a), «Nieblas, continuación», Ibid, 12-01.

- 1901b), «Nieblas, II», Ibid, 26-01.

- (1901c), «A la Alhambra», Ibid, 2-02.

- (1902), «A Dios», Ibid, 25-01.

- S/F(1900a), «En la Sorbona», Ibid, 22-12.

- (1900b), «La anarquía y Pi», Ibid, 15-12.

- (1900c), sin título, Ibid, 8-12.

SORIANO, Rodrigo (1900), «La nariz milagrosa», Ibid, 27-10.

TÁRrIDA DEL MÁRMOL, Fernando (1900), «Chamberlain», Ibid, 20-10.

Tcherkessoff, W. (1900), «La obra de Proudhon, (I)», Ibid, 15-12.

Vega CARpio, Lope de (1948), Arte nuevo de hacer comedias, Buenos Aires, Colección Austral, 842, pp.11-19.

ZEDA (F. Fernández Villegas) (1900), «París al día», Heraldo de París, 20-10.

Fecha de recepción: 31/03/2014

Fecha de aceptación: 02/09/2014 